\title{
REGULATION, OWNERSHIP FORM, AND THE ECONOMIC EFFICIENCY OF RURAL ELECTRIC DISTRIBUTION COOPERATIVES
}

\author{
Daniel R. Hollas and Stanley R. Stansell*
}

\begin{abstract}
This paper uses a translog profit function to analyze economic efficiency in rural electric distribution cooperatives for the period 1974-1982. Hypotheses dealing with absolute price efficiency, the effect of capital on profit and the effect of service area density on profit are tested. The paper uses a translog profit function analysis with both fixed and variable inputs to test the various hypotheses. Regulatory intensity variables are developed and used to examine the effect of regulation on technical efficiency. The results indicate that cooperatives are not profit maximizers, regulation has a negligible effect on technical efficiency, capital positively affects profit, and increasing service area density positively affects profit.
\end{abstract}

\section{INTRODUCTION}

The theory of the privately owned not-for-profit firm (the cooperative) has been extensively examined in the literature on agricultural cooperatives, credit unions, and various types of labor-managed cooperatives. Relatively little empirical work, however, has been performed to evaluate the distribution cooperative. In this country, rural electric distribution cooperatives (hereafter, RECs) have been studied by Mikesell and Mann (1976) and Neuberg (1977), and rural telephone cooperatives have been analyzed by Stansell (1980).

Studies by Dahlman (1979), DeAlessi (1974, 1975, 1983), Demsetz (1964, 1966, 1967), and Furbotn and Pejovich (1972) suggest that the different structures of property rights result in cost-reward distributions which systematically affect economic outcomes. The literature also suggests that the effects of regulation on economic efficiency depend on the structure of property rights.

It has been hypothesized that publicly owned firms differ substantially from privately owned firms in terms of economic efficiency. Jensen and Meckling (1976) developed a theory of agency in which the costs of monitoring and bonding play an essential role. They noted the importance of both the system of property rights and the firm's internal organization in a subsequent article (1979).

\footnotetext{
*Daniel R. Hollas, Associate Professor of Economics, The University of Texas at San Antonio, and Stanley R. Stansell, Robert Dillard Teer Distinguished Professor of Business, East Carolina University
} 
The theory suggests that the owners of public firms have reduced incentives to enforce contracts and develop internal controls. Public firms differ from private firms in terms of economic behavior because of reduced opportunities to specialize in ownership and, hence, risk, and their inability to capitalize future events into the value of the firm. Property rights in publicly owned firms are in fact virtually nontransferable. Finally, no one has a right to claim the residual in a public firm. These same defects may exist in the cooperative.

The purpose of this study is to perform an empirical analysis of the economic efficiency of RECs. We analyzed a sample of over 900 RECs for the period 1974 1982. The productive efficiency of RECs affects a large number of consumers. As of the end of 1982, over eight million patron/owners were served by RECs. These cooperatives serviced 1,869,691 route miles of line in 46 states, Puerto Rico and the Virgin Islands. We used the literature on property rights and agency to examine the economic efficiency of RECs. The second section of the paper develops the methoclology which employs a system of translog profit and input demand equations. The data and the construction of a measure of regulatory stringency are presented next. Finally, the results of the hypothesis tests are discussed.

\section{DEVELOPMENT OF THE PROFIT FUNCTION}

\section{Economic, Price and Technical Efficiency}

Numerous studies have examined the productivity of the firm using various specifications of the production function. The profit function employed in this study allows the same tests possible with a production function and, in addition, allows tests of price efficiency. The development of the profit function is due in part to the work of Shephard (1953, 1970), McFadden (1962), Uzawa (1964), and Diewert (1973) and early empirical studies by Lau and Yotopoulos (1971, 1972), and Yotopoulos and Lau (1973). More recent studies by Atkinson and Halvorsen (1980), Hollas and Stansell (1988 a, 1988 b) and Stansell and Hollas $(1988,1990)$ have employed the profit function to analyze economic efficiency. Through these types of studies we are able to analyze economic efficiency in a much broader sense.

Price efficiency can be categorized as relative price efficiency and absolute price efficiency. This study tests for absolute price efficiency, which occurs when the value of the marginal product of each factor is equated to its factor price. Absolute price efficiency implies profit maximization. Cost minimization is a necessary precondition for absolute price efficiency. 
Given exogenously determined output prices, variable input prices, and fixed factors of production, one can obtain consistent estimates of the price and technical efficiency parameters by estimating the profit function. According to the duality theorems, an appropriate arbitrary functional form for the profit function corresponds to a concave production function. As Lau (1978) notes, the arbitrary profit function must be decreasing and convex in input prices and increasing in output prices.

For convenience, let $E^{l}$ denote the economic efficiency of regulated firms and $E^{2}$ denote the economic efficiency of nonregulated firms. Conceptually, we test whether $E^{l}=E^{2}$. Note that $E$ is a function of both price efficiency $k$ and technical efficiency $T$. If $T^{l}=T^{2}$ and $\mathrm{k}^{l}=k^{2}$, then $E^{1}=E^{2}$.

Differences in either technical or price efficiency may cause $E^{I} \neq E^{2}$. We assume the $k^{l}=k^{2}=k^{l}$ for all firms. If the technological level of regulated firms is denoted $T^{l}$ and unregulated firms is $T^{2}$ then we actually test whether:

$$
\begin{aligned}
& H_{o}: T^{1}=T^{2} \\
& H_{a}: T^{1} \neq T^{2}
\end{aligned}
$$

In the following section we specify a model for the purpose of evaluating the economic efficiency of RECs.

\section{Formulation of the Translog Profit Function}

The model developed in this section will allow a test of absolute price efficiency for cooperative electric distribution utilities. A two-equation system for normalized profit and labor demand is derived to perform the efficiency tests. Additional tests for regulatory effects upon profits will be presented later. Development of the theoretical model follows Lau and Yotopoulos $(1971,1972)$, and Yotopoulos and Lau (1973), while derivation of the translog model generally follows the contribution of Atkinson and Halvorsen (1980).

Actual normalized profit and actual input demand functions can be derived once an appropriate behavioral profit function is selected. We employ a modified translog functional form for the behavioral normalized profit function. Like Lau and Yotopoulos (1971, 1972), and Yotopoulos and Lau (1973), we treat capital as fixed in the short-run profit function. Behavioral profit is 


$$
\begin{aligned}
\ln \Pi^{b} & =\alpha_{O}+\alpha_{L} \ln \left(k_{L} P_{L}\right)+\beta_{k} \ln (K)+\beta_{D} \ln (D)+\sum_{i} \beta_{i} \ln \left(R_{i}\right) \\
& +\frac{1}{2} \gamma_{L L} \ln \left(k_{L} P_{L}\right)^{2}+\frac{1}{2} \beta_{k k} \ln (K)^{2}+\gamma_{L K} \ln \left(k_{L} P_{L}\right) \ln (K) \\
& +\sum_{i} \gamma_{L i} \ln \left(k_{L} P_{L}\right) \ln \left(R_{i}\right)+\sum_{i} \beta_{K i} \ln (K) \ln \left(R_{i}\right) \\
& +\frac{1}{2} \sum_{i} \sum_{g} \beta_{i g} \ln \left(R_{i}\right) \ln \left(R_{g}\right),
\end{aligned}
$$

where $P_{L}$ is the price of labor, $K$ is fixed capital, $D$ is service area density, the $R_{i}$ are regulatory variables, $\mathrm{kL}_{\mathrm{L}}$ represents a systematic rule of behavior for which profit maximization is one case $\left(\mathrm{kL}_{\mathrm{L}}=1\right), \beta_{\mathrm{ig}}=\beta_{\mathrm{gi}}$, and $\mathrm{i}, \mathrm{g}=1,2$.

Actual profit is

$$
\begin{aligned}
\ln \Pi^{a} & =\ln \left[1+\frac{\left(1-k_{L}\right)}{k_{L}}\left(\alpha_{L}+\gamma_{L L} \ln \left(k_{L} P_{L}\right)+\gamma_{L K} \ln (K)+\sum_{i} \gamma_{L i} \ln \left(R_{i}\right)\right)\right] \\
& +\alpha_{O}+\alpha_{L} \ln \left(k_{L} P_{L}\right)+\beta_{k} \ln (K)+\beta_{D} \ln (D)+\sum_{i} \beta_{i} \ln \left(R_{i}\right) \\
& +\frac{1}{2} \gamma_{L L} \ln \left(k_{L} P_{L}\right)^{2}+\frac{1}{2} \beta_{K K} \ln (K)^{2}+\gamma_{L K} \ln \left(k_{L} P_{L}\right) \ln (K) \\
& +\sum_{i} \gamma_{L i} \ln \left(k_{L} P_{L}\right) \ln \left(R_{i}\right)+\sum_{i} \beta_{K i} \ln (K) \ln \left(R_{i}\right) \\
& +\frac{1}{2} \sum_{i} \sum_{g} \beta_{i g} \ln \left(R_{i}\right) \ln \left(R_{g}\right),
\end{aligned}
$$

If $k_{L}=1$, the actual and behavioral normalized profit functions are identical. This implies $V M P_{L}=k_{L} P_{L}^{\prime}$, where $V M P_{L}$ is the value of marginal product, and $P_{L}^{\prime}$ is the non-normalized dollar price of labor. If $k_{L}<1$, input $L$ is overutilized relative to the profit maximizing level.

Factor demand for labor is expressed as the ratio of normalized expenditure on the factor to actual normalized profit,

$$
l_{L}=\frac{P_{L} X_{L}}{\Pi_{a}}
$$

which is, 


$$
\begin{aligned}
l_{L}= & -k_{L}^{-1}\left[\alpha_{L}+\gamma_{L L} \ln \left(k_{L} P_{L}\right)+\gamma_{L K} \ln (K)+\sum_{i} \gamma_{L i} \ln \left(R_{i}\right)\right] \\
& {\left[1+\left(\frac{1-k_{L}}{K_{L}}\right)\left(\alpha_{L}+\gamma_{L L} \ln \left(k_{L} P_{L}\right)+\gamma_{L K} \ln (K)\right.\right.} \\
& \left.\left.+\sum_{i} \gamma_{L i} \ln \left(R_{i}\right)\right)\right]^{-1} .
\end{aligned}
$$

Equation (2) for normalized profit and the labor input demand equation (3) comprise the system to be estimated. Note that the system of two equations, actual normalized profit (2), and the input demand equation for labor (3), is derived for normalized profit.

A normalized profit function is assumed to be strictly decreasing and convex in the normalized prices. The second derivative of the normalized profit function with respect to the wage must be positive to meet the convexity assumption. The fitted values of the ratio of normalized expenditure on the factor to actual normalized profit must be positive for monotonicity. For a discussion, see Lau (1978).

\section{THE DATA}

Data on the financial and operating statistics of the RECs examined in this study were obtained from the Rural Electrification Administration (REA). The data set covers the time span from 1974 through 1982. Because all RECs are required to use a standardized accounting and reporting system by the REA, the data are believed to be highly comparable and internally consistent.

Profit $(\pi)$ is calculated by subtracting maintenance and operating expenses (other than cost of purchased power) from operating revenue. Because the cost of purchased power is set under long-term contracts, it is a fixed expense and is not deducted. Therefore, our measure of profits is operating revenue minus variable costs. Output price is calculated by dividing operating revenues by $\mathrm{KWH}$ sold. The price of labor $\left(P_{L}\right)$ is calculated by dividing total payroll by total hours worked. The amount of capital $(K)$ is equal to the dollar value of net utility plant. Density $(D)$ is measured by consumers per mile of distribution line. The profit function is normalized by the output price. Descriptive statistics for the data are available on request. 
The regulatory data used in this study were obtained from the Annual Report on Utility and Carrier Regulation, 1974-1982, published by the National Association of Regulatory Utility Commissioners. The primary regulatory data set consists of 46 state-level variables covering an extensive range of regulatory information.

\section{Construction of the Regulatory Variables}

In order to reduce the number of variables and yet capture as much of the regulatory information as possible, a cross-sectional principal components analysis was conducted using the natural log of profits as the dependent variable,

$$
\ln (\Pi)=a_{1} X_{1}+\ldots . a_{46} X_{46}
$$

where $\Pi=$ profit and $X_{i}=$ the 46 regulatory variables. This technique was employed by Hollas and Stansell (1988). ${ }^{1}$ The variables include data on rates and rate changes, fuel adjustment clauses, rate base valuation, number of commissioners and compensation, the Duff-Phelps rating, commissioner selection method and term, and depreciation method. Detailed information is available on request.

The first two principal components from each of the separate principal components analyses are then used to construct two regulatory variables which are then used in the profit function analysis for each of the nine years. Approximately 30 percent to 40 percent of the total variation in profits is explained each year by the first two principal components. This procedure allows the model to capture an extensive amount of regulatory climate information in the form of two variables. Since RECs are regulated in some states but not in others, we constructed a "zeroone" dummy variable which has a value of one if regulation exists in that state and zero if it does not, and multiplied it by the first and second principal components. If RECs are not regulated in a given state, the two principal components are multiplied by zero and have a product of zero for that state for that year. If RECs are regulated, the two principal components are multiplied by one. The products are two separate variables, referred to hereafter as $Z l$ and $Z 2$, which reflect whether or not RECs are regulated in a given state and, if regulated, reflect in a continuous fashion much of the information in the full 46 variable regulatory data set. Because the regulatory variables $Z l$ and $Z 2$ can be positive, zero, or negative, we enter these variables into the profit function equation (2) as $R_{I}=e^{Z I}$ and $R_{2}=e^{Z 2}$, respectively. 


\section{Regional Aspects of REC Operations}

The regional impact of RECs varies widely. Several states (Connecticut, Hawaii, Massachusetts, and Rhode Island) have none. In states such as Georgia, Tennessee, and Texas, the number of customers served is quite large. As indicated in Table 1, from 1974 to 1982 the number of customers served in the United States increased by 30.4 percent, from 7,431,432 to $9,687,382$. Since miles of line energized increased by 13.4 percent from $1,760,842$ to $1,997,068$, we may conclude that the increase is attributable to increasing population density rather than increasing service area. From Table 1, the number of RECs increased 5 percent from 981 in 1974 to 986 in 1982 . While RECs provide service nationwide, they primarily serve the Southeast, Southwest, and some states in the Midwest and Rocky Mountain regions. Given the rural nature of their service areas, this distribution is to be expected.

The analysis conducted in this study is performed on a cross-sectional national sample for each year from 1974 through 1982. There is no way to infer from the results anything on a regional or state basis other than that if RECs serve a large number of customers in a given area, anything that affects RECs will affect that area.

In Table 2, descriptive data on the number of utilities by state (segregated into public, private, and cooperatives and the regulatory status) are presented for the years 1974 and 1982. In 1982, approximately half of the states did not regulate or control rates on cooperatives.

\section{RESULTS OF THE EMPIRICAL TESTS}

The unconstrained model as specified in Equations (2) and (3) was estimated using cross-sectional data for the years 1974 through 1982. Estimates of the coefficients for the unconstrained model are reported in Table 3.

Virtually every fitted observation met convexity and monotonicity requirements between 1975 and 1982. In 1974, when the industry apparently was in disequilibrium-possibly due to the oil embargo-very few observations passed the convexity requirements. Also, the fitted values of the labor demand function were evaluated using the monotonicity test. Again, except for 1974, virtually every value passed the monotonicity requirement.

Constraints were imposed on the model to allow tests for absolute price efficiency, regulatory effects, the effect of service area density, and the effect of fixed capital on profits. The hypotheses and model restrictions are specified below. 
TABLE 1

REC Data By State, 1974, 1982

\begin{tabular}{|c|c|c|c|c|c|c|c|c|}
\hline \multirow[t]{2}{*}{ State } & \multicolumn{2}{|c|}{$\begin{array}{l}\text { Number of } \\
\text { ctive Borrowers }\end{array}$} & \multicolumn{2}{|c|}{$\begin{array}{l}\text { Number of Full- } \\
\text { Time Employees }\end{array}$} & \multicolumn{2}{|c|}{$\begin{array}{c}\text { Miles of Line } \\
\text { Energized }\end{array}$} & \multicolumn{2}{|c|}{ Consumers Served } \\
\hline & 1974 & 1982 & 1974 & 1982 & 1974 & 1982 & 1974 & 1982 \\
\hline \multicolumn{9}{|l|}{ UNITED } \\
\hline STATES & 981 & 986 & 42,908 & 55,258 & $1,760,842$ & $1,997,068$ & $7,431,432$ & $9,687,382$ \\
\hline Alabama & 24 & 24 & 1,440 & 1,656 & 47,112 & 52,557 & 292,160 & 352,036 \\
\hline Alaska & 13 & 15 & 594 & 835 & 5,559 & 7,829 & 65,449 & 117,072 \\
\hline Arizona & 10 & 11 & 387 & 924 & 8,319 & 13,721 & 49,787 & 97,598 \\
\hline Arkansas & 20 & 20 & 1,270 & 1,404 & 50,175 & 56,483 & 220,001 & 274,631 \\
\hline Califomia & 5 & 5 & 58 & 100 & 3,343 & 3,664 & 43,698 & 32,850 \\
\hline Colorado & 24 & 24 & 1,195 & 2,733 & 44,733 & 55,687 & 152,095 & 249,876 \\
\hline Connecticut & 0 & 0 & 0 & 0 & 0 & 0 & 0 & 0 \\
\hline Delaware & 1 & 1 & 102 & 91 & 2,788 & 3,225 & 23,769 & 31,671 \\
\hline Florida & 15 & 16 & 1,698 & 2,295 & 36,618 & 43,974 & 268,219 & 423,089 \\
\hline Georgia & 42 & 44 & 2,413 & 3,354 & 2,525 & 101,590 & 502,902 & 720,030 \\
\hline Hawaii & 0 & 0 & 0 & 0 & 0 & 0 & 0 & 0 \\
\hline Idaho & 9 & 9 & 195 & 245 & 9,175 & 10,843 & 29,294 & 40,913 \\
\hline Illinois & 29 & 29 & 1,134 & 1,210 & 50,251 & 52,925 & 174,259 & 204,417 \\
\hline Indiana & 42 & 43 & 1,236 & 1,540 & 44,497 & 49,060 & 258,672 & 331,472 \\
\hline Iowa & 53 & 52 & 1,326 & 1,246 & 61,151 & 64,168 & 156,192 & 172,089 \\
\hline Kansas & 37 & 36 & 824 & 1,237 & 60,753 & 68,864 & 118,458 & 165,724 \\
\hline Kentucky & 28 & 28 & 2,198 & 3,041 & 63,628 & 70,123 & 354,657 & 443,368 \\
\hline Louisiana & 15 & 15 & 979 & 1,826 & 35,545 & 40,595 & 203,421 & 291,604 \\
\hline Maine & 3 & 4 & 42 & 54 & 1,374 & 1,682 & 8,891 & 12,185 \\
\hline Maryland & 2 & 2 & 493 & 426 & 8,326 & 9,958 & 67,480 & 90,079 \\
\hline Massachusetts & 0 & 0 & 0 & 0 & 0 & 0 & & 0 \\
\hline Michigan & 15 & 15 & 600 & 598 & 25,874 & 28,809 & 152,453 & 181,043 \\
\hline Minnesota & 52 & 50 & 1,983 & 2,625 & 93,704 & 104,569 & 332,832 & 421,867 \\
\hline Mississippi & 25 & 24 & 2,060 & 2,192 & 62,540 & 67,879 & 344,189 & 408,670 \\
\hline Missouri & 47 & 47 & 2,275 & 2,909 & 98,073 & 105,801 & 355,679 & 422,074 \\
\hline Montana & 24 & 25 & 398 & 523 & 36,849 & 42,166 & 65,876 & 88,558 \\
\hline Nebraska & 35 & 35 & 793 & 855 & 62,787 & 68,825 & 123,292 & 50,567 \\
\hline Nevada & 7 & 8 & 107 & 128 & 3,803 & 4,543 & 9,703 & 15,501 \\
\hline New Hampshire & 1 & 1 & 178 & 179 & 3,575 & 4,007 & 36,503 & 45,917 \\
\hline New Jersey & 1 & 1 & 20 & 40 & 362 & 420 & 5,683 & 7,908 \\
\hline New Mexico & 17 & 17 & 626 & 858 & 30,696 & 35,979 & 88,922 & 119,355 \\
\hline New York & 4 & 4 & 62 & 63 & 2,167 & 2,461 & 8,688 & 10,607 \\
\hline North Carolina. & 28 & 28 & 1,489 & 1,708 & 53,879 & 61,904 & 357,781 & 455,160 \\
\hline North Dakota & 25 & 26 & 968 & 2,308 & 58,028 & 64,856 & 77,172 & 94,153 \\
\hline Ohio & 28 & 28 & 853 & 899 & 34,677 & 37,958 & 191,023 & 229,602 \\
\hline Oklahoma & 28 & 28 & 1,560 & 1,821 & 78,255 & 8,875 & 226,613 & 314,479 \\
\hline Oregon & 14 & 15 & 437 & 506 & 16,957 & 20,554 & 65,601 & 97,086 \\
\hline Pennsylvania & 12 & 13 & 613 & 624 & 21,257 & 23,472 & 126,734 & 153,735 \\
\hline Rhode Island & 0 & 0 & 0 & 0 & 0 & 0 & 0 & 0 \\
\hline South Carolina & 22 & 21 & 1,130 & 1,335 & 42,428 & 48,882 & 244,991 & 325,919 \\
\hline South Dakota & 34 & 34 & 731 & 802 & 56,182 & 62,093 & 89,879 & 103,679 \\
\hline Tennessee & 24 & 24 & 1,851 & 1,956 & 54,641 & 61,078 & 464,347 & 565,129 \\
\hline Texas & 80 & 80 & 3,494 & 4,478 & 196,077 & 28,006 & 628,668 & 866,567 \\
\hline Utah & 5 & 5 & 141 & 221 & 4,156 & 5,010 & 12,820 & 20,116 \\
\hline Vermont & 2 & 2 & 109 & 90 & 2,440 & 2,598 & 12,995 & 16,279 \\
\hline Virginia & 15 & 14 & 1,024 & 1,047 & 31,201 & 34,906 & 183,901 & 232,438 \\
\hline Washington & 16 & 16 & 350 & 416 & 15,849 & 17,838 & 55,554 & 77,399 \\
\hline West Virginia & 1 & 1 & 20 & 15 & 655 & 704 & 3,418 & 4,224 \\
\hline Wisconsin & 30 & 30 & 1,203 & 1,369 & 36,000 & 40,029 & 134,369 & 162,463 \\
\hline Wyoming & 15 & 14 & 321 & 440 & 21,723 & 25,898 & 42,342 & 66,183 \\
\hline
\end{tabular}

Source: Annual Statistical Report, Rural Electric Borrowers, 1974-1982, Rural Electrification Administration. 


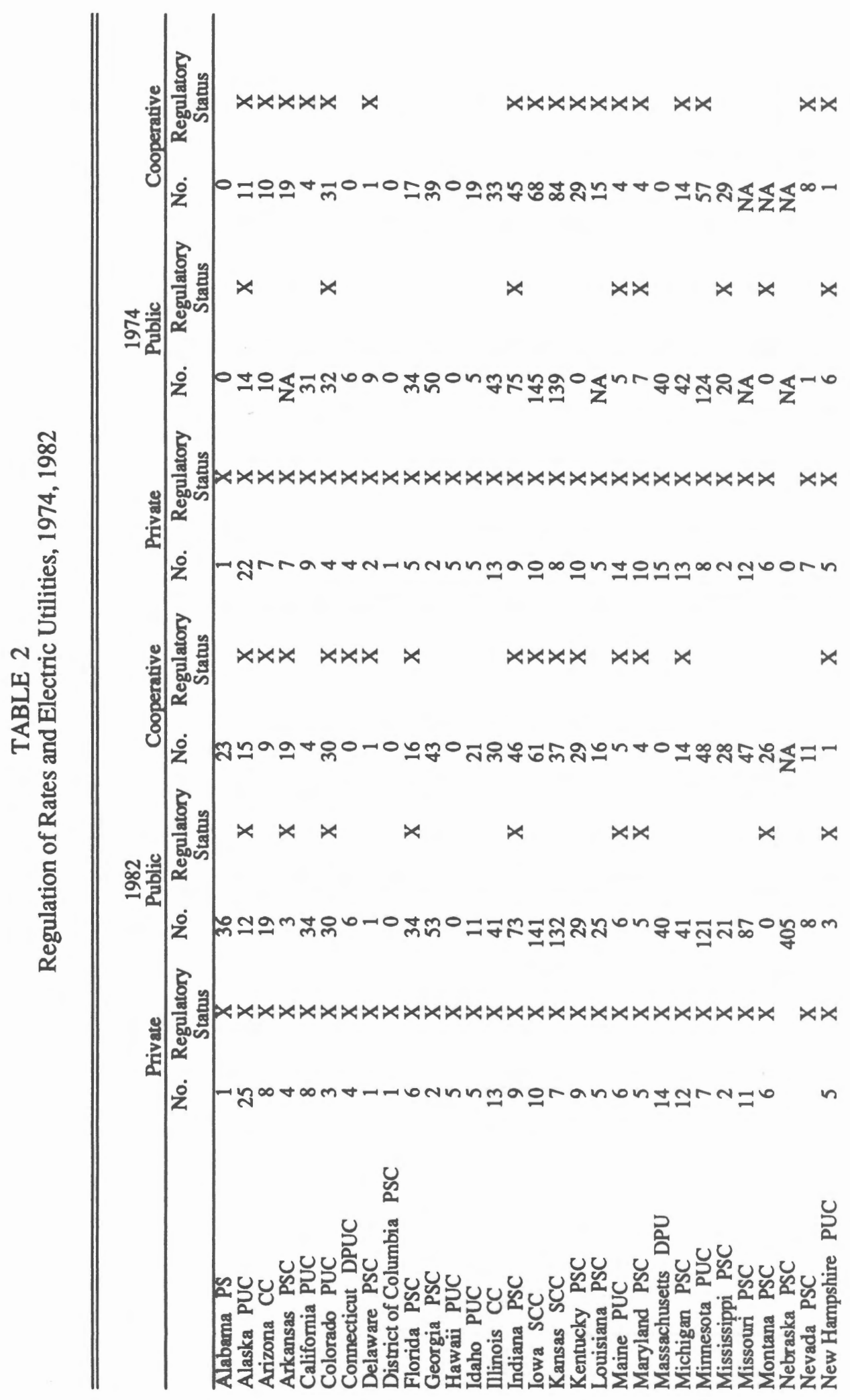




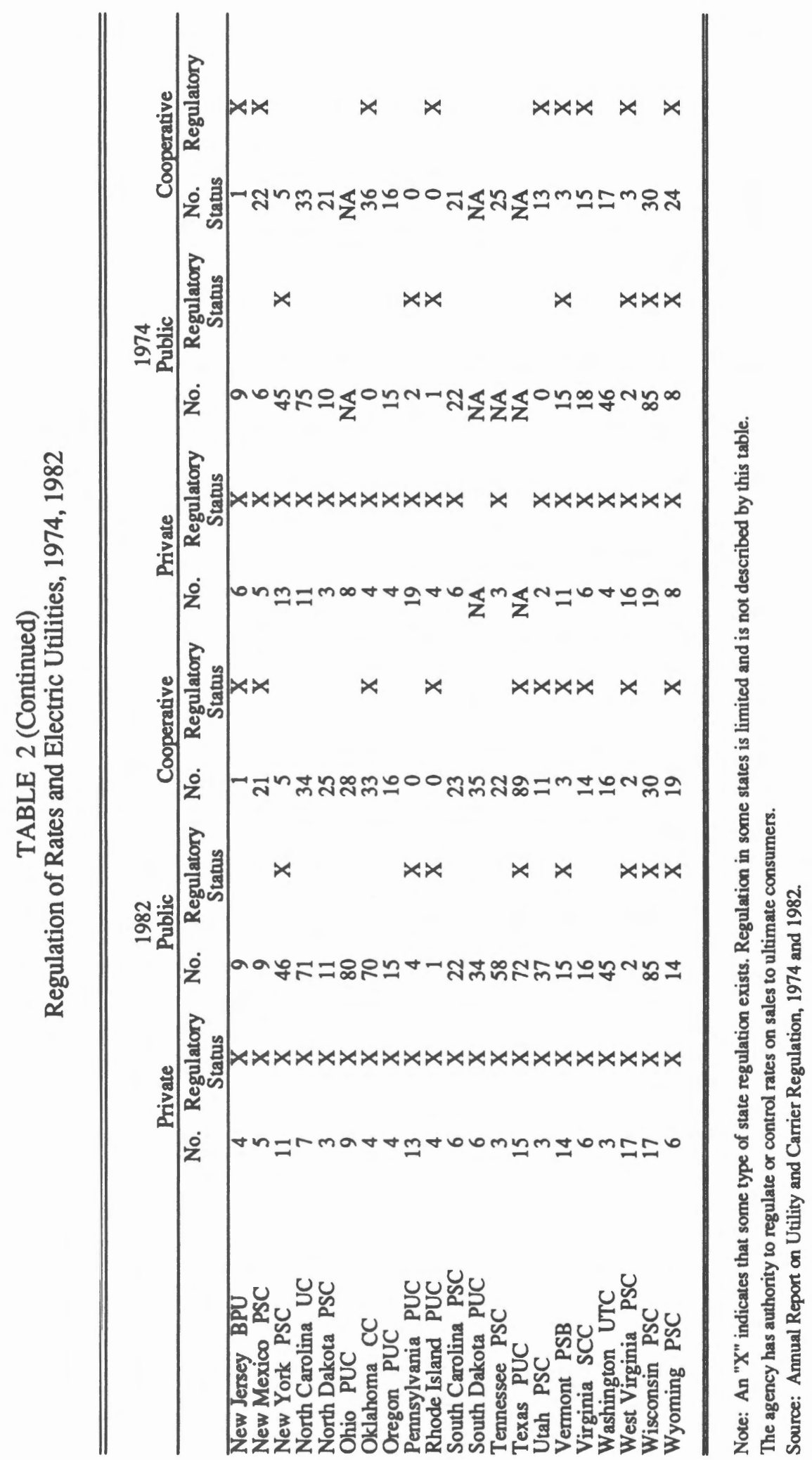




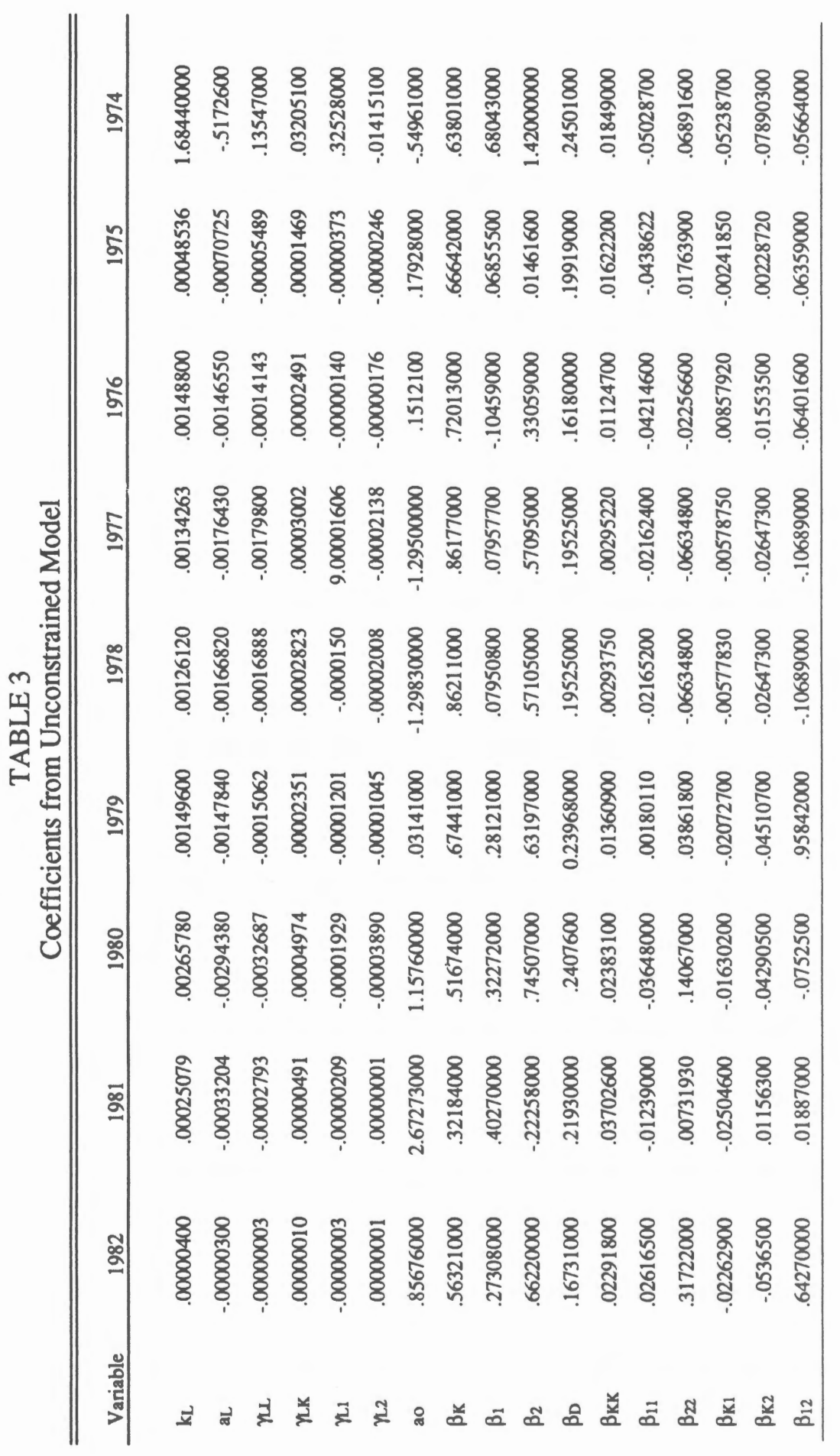




\section{A Test for Absolute Price Efficiency}

In our model the only variable input is labor. We therefore are able to test only for absolute price efficiency.

Hypothesis 1. RECs are absolute price efficient in the use of labor.

$$
\begin{aligned}
& H_{o}: k_{L}=1.0 \\
& H_{a}: k_{L} \neq 1.0
\end{aligned}
$$

If $k_{L}<1.0$, this implies overutilization of labor, and vice versa.

From an inspection of Tables 3 and 4, we reject the null hypothesis of absolute price efficiency in each of the nine years examined. Since $k_{L}<1.0$ in all years except 1974, we conclude that electric distribution cooperatives overutilize labor. This confirms the conventional view that cooperatives are not profit-maximizing firms. The evidence indicates that the industry was going through an adjustment period in 1974 due to the oil embargo.

Since in every year except 1974 the $k L$ are very close to zero in value, we conclude that the value of the marginal product of labor is virtually zero. This indicates that on average, RECs are very close to the boundary between stage two and stage three of the production function where the marginal physical product of labor equals zero. The industry, therefore, appears to be overutilizing labor to a significant degree, beyond a profit-maximizing level and certainly beyond the level at which the average variable cost curve is at a minimum. A rationally managed REC might either engage in profit-maximization behavior with dividend repatriation of profits or, more probably, operate at the output level which minimizes per unit costs. Since RECs appear to be price takers in the output market and must serve all customers, they can control neither prices nor membership. Thus, they have no control over output in the long run. The evidence indicates that the firm operates near the point at which total revenue is maximized. These results are consistent with those of Paroush and Kahana (1980), who found that cooperatives, even if risk averse, would produce more and demand more labor input under conditions of price uncertainty than their capitalist twin.

Although direct comparisons of the economic efficiency of REC and private electric distributors are not possible in this study, a previous study by Hollas and Stansell (1988) of private, municipal, and cooperative electric generating utilities concludes that none of the three ownership forms is absolute price efficient (a profit maximizer), nor is any of the three relative price efficient (a cost minimizer). For the four years examined (1977-1980), there is no evidence that any of 
TABLE 4

$\chi^{2}$ Statistics Log Likelihood Ratio Tests

\begin{tabular}{|c|c|c|c|c|c|c|c|c|c|c|c|}
\hline No. & D.F. & $x^{2}$ & 1982 & 1981 & 1980 & 1979 & 1978 & 1977 & 1976 & 1975 & 1974 \\
\hline 1 & 1 & 6.64 & 12.84 & 19.80 & 22.80 & 18.32 & 12.34 & 12.34 & 80.12 & 43.64 & 58.68 \\
\hline 2 & 9 & 21.67 & 920.30 & 25.64 & 32.44 & 39.52 & 91.94 & $1,036.92$ & 25.64 & 860.84 & 280.08 \\
\hline 3 & 4 & 13.27 & 15.14 & 30.28 & $42,159.98$ & $39,80.46$ & 23.34 & $4,234.10$ & 26.12 & $4,484.66$ & $3,741.74$ \\
\hline 4 & 1 & 6.64 & 313.10 & 96.44 & 110.24 & 105.04 & 842.88 & 76.02 & 53.86 & 73.32 & 91.58 \\
\hline
\end{tabular}

a: $\chi^{2}$ critical value, .01 significance level.

the forms consistently leads to absolute price efficiency in the use of labor. However, privates consistently (all four years) came closer to employing the profitmaximizing levels of labor and fuel than did cooperatives. Although no pure distribution utilities were included in the previous analysis, the results of that study possibly suggest that a rural private distributor might be more absolute price efficient in the use of labor than a rural cooperative distributor of electricity, especially given the tendency of the cooperatives sampled in this study to employ labor up to the boundary of the second and third stages of the short-run production function.

\section{A Test for Regulatory Effects on Total Profit}

If regulation affects total profit, the coefficients of one of the regulatory variables or interaction terms must be significantly different from zero.

Hypothesis 2. Regulation affects the economic efficiency of RECs.

$$
\begin{gathered}
H_{o}: \gamma_{L 1}=\gamma_{L 2}=\beta_{1}=\beta_{2}=\beta_{K 1}=\beta_{K 2}=\beta_{11}=\beta_{12}=\beta_{22}=0 \\
H_{a}: \gamma_{L 1} \neq 0 \text { or } \gamma_{L 2} \neq 0 \text { or } \beta_{1} \neq 0 \text { or } \beta_{2} \neq 0 \text { or } \beta_{K 1} \neq 0 \text { or } \\
\beta_{K 2} \neq 0 \text { or } \beta_{11} \neq 0 \text { or } \beta_{12} \neq 0 \text { or } \beta_{22} \neq 0
\end{gathered}
$$

If all of the coefficients of the regulatory variables and their interactions are equal to zero, regulation has no effect on profits. If the coefficients are negative in sign and significant, regulation has a negative effect on profits, and vice versa.

The empirical results reported in Tables 3 and 4 indicate that regulation significantly affects total profit. Since it is difficult to directly interpret these results due to the mixed signs, in order to gain some insight into the effects we calculate elasticities of actual profit with respect to regulation: 


$$
\begin{aligned}
& E_{R i}=\frac{\partial \ln \Pi^{a}}{\partial \ln R_{i}}=\beta_{i}=\gamma_{L i} \ln \left(k_{L} P_{L}\right)+\beta_{k i} \ln (K)+\beta_{i i} \ln \left(R_{i}\right)+\beta_{i g} \ln \left(R_{g}\right) \\
& +\left[\frac{\left(1-k_{L}\right)}{k_{L}} \gamma_{L i}\right]\left[1+\frac{\left(1-k_{L}\right)}{k_{L}}\left(\alpha_{L}+\gamma_{L L} \ln \left(k_{L} P_{L}\right)+\gamma_{L K} \ln (K)+\sum_{i} \gamma_{L i} \ln \left(R_{i}\right)\right)\right]-1
\end{aligned}
$$$$
\text { for } i, g=1,2 ; i \neq g \text {. }
$$

The net effect of regulation is shown as the sum of $E_{R 1}$ and $E_{R 2}$ in Table 5.

We have calculated $E_{R 1}$ and $E_{R 2}$ under two different behavioral assumptions: first, assuming profit maximization behavior $\left(k_{L}=1\right)$; and second, assuming not-for-profit behavior $\left(k_{L} \neq 1\right)$. If we assume profit maximization behavior, regulation has a negative effect in every year. Except for 1974, the coefficients are small in magnitude. If we assume that the firms are not profit maximizers (as our results indicate) the coefficients are very small in magnitude for most years and have mixed signs. We conclude that regulation has a negligible effect on profit in six of the nine years studied.

TABLE 5

\begin{tabular}{|c|c|c|c|c|c|c|}
\hline & \multicolumn{3}{|c|}{$\begin{array}{l}\text { Assuming Profit } \\
\text { Maximization } \\
\left(\mathbf{k}_{\mathrm{L}}=1.0\right)\end{array}$} & \multicolumn{3}{|c|}{$\begin{array}{l}\text { Assuming Non-Profit } \\
\text { Maximization } \\
(\mathbf{k L} \neq 1.0)\end{array}$} \\
\hline & $\mathrm{ER}_{\mathrm{R}}$ & $E_{R 2}$ & $E_{R 1}+E_{R 2}$ & $\mathrm{ER}_{\mathrm{R}}$ & $E_{R 2}$ & $E_{R 1}+E_{R 2}$ \\
\hline 1982 & -.009 & .006 & -.003 & -.007 & .088 & .081 \\
\hline 1981 & -.017 & .006 & -.011 & -.004 & -.003 & -.007 \\
\hline 1980 & -.019 & -.067 & -.086 & .003 & -.007 & -.004 \\
\hline 1979 & -.021 & -.023 & -.044 & .004 & .226 & .230 \\
\hline 1978 & -.036 & -.050 & -.086 & -.014 & .010 & -.004 \\
\hline 1977 & -.047 & -.041 & -.088 & .015 & .018 & .003 \\
\hline 1976 & -.037 & -.021 & -.058 & -.007 & .010 & .003 \\
\hline 1975 & -.024 & -.042 & -.066 & -.004 & -.005 & -.009 \\
\hline 1974 & -.132 & .020 & -.112 & .383 & .042 & .425 \\
\hline
\end{tabular}

Mean Elasticities of Actual Profit with Respect to Regulation 
A study by Arzac and Edwards (1979) suggests that conflicting forces are simultaneously operating on the regulated firm. If the firm engages in expense preference behavior and is regulated, it may employ too little capital. If the firm is rate-of-retum regulated, it may employ too much capital. The two forces may offset each other.

\section{A Test for the Effect of the Amount of Capital on Marginal Profit}

We next examine the effect of capital on profit. $^{2}$

Hypothesis 3. Capital usage affects marginal profit.

$$
\begin{aligned}
& H_{o}: \beta_{K K}=\gamma_{L K}=\beta_{K 1}=\beta_{K 2}=0 \\
& H_{a}: \beta_{K K} \neq 0 \text { or } \gamma_{L K} \neq 0 \text { or } \beta_{k 1} \neq 0 \text { or } \beta_{K 2} \neq 0
\end{aligned}
$$

We reject the null hypothesis in every year. The overall effect of the amount of capital on marginal profit is positive. However, overutilization of capital may have occurred during the period examined. Capital subsidies were provided to the RECs by the REA. During the period examined in this study, loans were available for capital expansion at interest rates significantly below the prevailing open market rate. Further, rates on these loans did not reflect risk differentials between cooperatives. Such policies certainly encourage overutilization of capital. In other words, the effective price of capital is lower than the market price of capital due to subsidies, and thus is lowered relative to the market price of labor. This distortion creates an additional incentive to substitute capital for labor. The extent to which RECs are (relative price) inefficient in the long-run substitution of capital and labor could be significant. Since we consider capital a fixed input, we cannot directly test this proposition; we merely conclude that RECs are not absolute price efficient in the short-run use of labor.

We next calculate a measure of the responsiveness of output to a change in the fixed capital input. An appropriate measure of the responsiveness of profit (and, by duality, production) is the elasticity of profit with respect to capital:

$$
\begin{aligned}
& E_{K}=\beta_{k}+\beta_{K K} \ln (K)+\gamma_{L K} \ln \left(k_{L} P_{L}\right)+\sum_{i} \beta_{k i} \ln \left(R_{i}\right) \\
& +\left[\frac{\left(1-k_{L}\right)}{k_{L}} \gamma_{L K}\right]\left[1+\frac{\left(1-k_{L}\right)}{k_{L}}\left(\alpha_{L}+\gamma_{L L} \ln \left(k_{L} P_{L}\right)+\gamma_{L K} \ln (K)+\sum_{i} \gamma_{L i} \ln \left(R_{i}\right)\right)\right]-1
\end{aligned}
$$


TABLE 6

Mean Elasticity of Profit with Respect to Capital

\begin{tabular}{ccc}
\hline \hline & $\begin{array}{c}\text { Assuming Profit } \\
\text { Maximization } \\
\left(\mathbf{k L}_{\mathrm{L}}=1.0\right)\end{array}$ & $\begin{array}{c}\text { Assuming Non-Profit } \\
\text { Maximization } \\
\left(\mathrm{E}_{\mathrm{L}} \neq 1.0\right)\end{array}$ \\
\hline 1982 & .935 & $\mathrm{E}_{\mathrm{K}}$ \\
1981 & .908 & .159 \\
1980 & .888 & .177 \\
1979 & .887 & .202 \\
1978 & .929 & .228 \\
1977 & .926 & .262 \\
1976 & .930 & .281 \\
1975 & .951 & .313 \\
1974 & .914 & .355 \\
\hline
\end{tabular}

Mean elasticities of profit with respect to capital for each year are reported in Table 6. We again perform the calculation under both an assumption of profit maximization behavior and not-for-profit behavior. Our elasticity estimates of actual profit with respect to capital (EK) reported in Table 6 indicate that $\mathrm{E}_{\mathrm{K}}<1.0$ in every year; it appears that the average product of capital exceeds the marginal product of capital, indicating that cooperatives operate near the third stage of production.

Embodied technical change implies that technological improvements are embedded in capital. An examination of Table 6 indicates that, assuming not-forprofit behavior, all values of the elasticity of profit with respect to the amount of capital are positive in sign and between 0.159 and 0.396 in value. Our model does not allow us to examine the separate effects of embodied technology versus the amount of capital on profit. We may, however, examine the responsiveness of profit and, by duality, production to capital. From 1974 through 1982, the coefficients decrease in magnitude by 0.237 , implying a small decrease in responsiveness. This may imply a slight downward trend in embodied technical change.

The elasticity of profit $E_{K}$ reported in Table 6 is less than 1.0 in every case, which implies that there may be diseconomies of scale in the cooperative distribution of electricity. However, since only capital expansion is reflected in $E_{K}$ and not expansion of all inputs (i.e., this change is not on the expansion path), no strong conclusions are warranted concerning production economies. Under both behavioral assumptions, the elasticities are positive. They are significantly smaller if not-for-profit behavior is assumed, and there is a significant downward trend in the elasticities, suggesting that profits are less responsive to the amount of capital 
in recent years. These results are consistent with the position that diseconomies of scale exist, although as noted earlier, this conclusion should be viewed with caution. Neuberg (1977) suggests that, while very large municipal distribution firms are probably greater than the optimal size, very small firms may be well under the optimal size.

\section{A Test for the Effect of Service Area Density}

If service area density affects total profit, the coefficient of the service area density variable $\beta_{D}$ should be significantly different from zero. Our hypothesis may be formally stated:

Hypothesis 4. Service area density affects economic efficiency.

$$
\begin{aligned}
& H_{o}: \beta_{D}=0 \\
& H_{a}: \beta_{D} \neq 0
\end{aligned}
$$

As the results reported in Table 4 indicate, the null hypothesis is rejected in every year. The coefficients of $B_{D}$ reported in Table 3 indicate that service area density has a positive effect on firms' profits. However, Mikesell and Mann (1976) found that service area density did not affect REC pricing practices.

\section{CONCLUSIONS}

The property rights and agency theory literature suggests that cooperative firms, even though privately owned, should not be as economically efficient as profit-maximizing firms. The results of the tests conducted in this study indicate that cooperatives in fact do not maximize profits because absolute price efficiency is rejected. Cooperatives appear to overutilize labor inputs. Given that we reject profit maximization behavior and conclude that not-for-profit behavior exists, regulation's effects are negligible and mixed in sign. Service-area density has a positive effect on total profit. The elasticity of profit estimates suggest that the effect of the amount of capital on profits (i.e., economic efficiency) is positive.

Meade (1974) analyzes the labor-managed cooperative and concludes that it will add workers as long as the marginal revenue value of their marginal product is greater than the current income per worker available for distribution to labor. While the RECs analyzed in their study are not labor managed, the results obtained in this study are consistent with such behavior. 
These results are not consistent with the conventional theory of natural monopoly. The industry may be experiencing diseconomies of scale. From a policy standpoint, our results indicate that capital subsidies to RECs are difficult to justify.

The REC may have a different objective function from that of a profit-maximizing firm. It is difficult to reconcile the results obtained from this study with any mode of behavior that is consistent with the maximization of the utility of the cooperative's patron/owners. Maximization of total revenue, which seems to be consistent with our results, is not consistent with either minimization of per-unit cost or profit maximization.

The regional implications of our results must be couched in terms of REC service intensity by state (shown in Table 3 ). In certain states (and, generally, certain geographic areas) RECs serve a significant number of rural customers. In particular, the Southeast, Southwest, and Rocky Mountain region would be significantly affected by any policy changes affecting RECs.

Regulation does not appear to have a strong impact on RECs. Many states do not even regulate them. Our empirical results indicate that regulatory effects are neither substantial nor consistent from period to period. The broad results of our study suggest that on average diseconomies of scale may exist, that capital subsidies could be reduced, and that the benefits from technological change are declining. In the regions where RECs serve significant customer bases, these results indicate that public policies that reduce REC size and capital subsidies, and encourage an examination of the type and level of capital employed, might improve the economic efficiency of RECs.

\section{ENDNOTES}

1. There are many facets of electric utility regulation, some more important than others. Since capital is treated as a fixed input, rate-of-return regulation should not distort the results of this study through an Averch-Johnson effect. However, other institutional aspects of regulation, such as how "close" public service commissioners are to their constituents, are not highlighted by a principal component analysis. See (Boyes and McDowell 1989) for a recent study on the role of institutional setting in the pricing of electricity by private utilities.

2. Although we do not report the statistical results, the null hypothesis $\beta_{k}=0$ is rejected in each year at the .05 level of significance. 


\section{REFERENCES}

Arzac, E. R., and F. R. Edwards. "Efficiency in Regulated and Unregulated Firms: An Iconoclastic View of the Averch-Johnson Thesis." Problems in Public Utility Economics and Regulation. Ed., M.A. Crew. Lexington, Mass.: D.C. Heath \& Co., 1979, 48.

Atkinson, S. E., and R. Halvorsen. "A Test of Relative and Absolute Price Efficiency in Regulated Utilities." The Review of Economics and Statistics 62, No. 1 (February 1980): 81-88.

Boyes, W. J., and J. M. McDowell. "The Selection of Public Utility Commissioners: A Reexamination of the Importance of Institutional Setting." Public Choice 61 (1989): 1-13.

Dahlman, C. J. "The Problem of Externalities." The Journal of Law and Economics 21, No. 1 (April 1979): 141-162.

De Alessi, L. "An Economic Analysis of Government Ownership and Regulation." Public Choice 19 (Fall 1974): 1-42.

"Some Effects of Ownership on the Wholesale Prices of Electric Power."

Economic Inquiry 13 (December 1975): 526-538.

. "Property Rights, Transaction Costs, and X-Efficiency: An Essay in

Economic Theory." The American Economic Review 73 (March 1983): 64-81.

Demsetz, H. "The Exchange and Enforcement of Property Rights." The Journal of Law and Economics 9 (October 1964): 11-26. . "Some Aspects of Property Rights." The Journal of Law and Economics 9 (October 1966): 61-70.

. "Toward A Theory of Property Rights." The American Economic Review 57, No. 2 (May 1967): 347-359.

Diewert, W. E. "Functional Forms for Profit and Transformation Functions." Journal of Economic Theory 6, No. 3 (1973): 284-316.

Furubotn, E. G., and S. Pejovich. "Property Rights and Economic Theory: A Survey of Recent Literature." Journal of Economic Literature (December 1972): 1137-1162.

Hollas, D. R., and S. R. Stansell. "An Examination of the Effect of Ownership Form on Price Efficiency: Proprietary, Cooperative and Municipal Electric

Utilities." Southern Economic Journal 55, No. 2 (October 1988): 336-350.

Jensen, M. C., and W. H. Meckling. "Theory of the Firm: Managerial Behavior, Agency Costs and Ownership Structure." Journal of Financial Economics 3, No. 4 (October 1976): 305-360.

"Rights and Production Functions: An Application to Labor-Managed Firms and Codetermination." Journal of Business 52, No. 4 (1979): 469-560. 
- "Regulation, Interfirm Rivalry and the Economic Efficiency of Natural Gas Distribution Utilities." Quarterly Review of Economics and Business 28, No. 4 (1988): 21-37.

Lau, L. J., and P. A. Yotopoulos. "A Test for Relative Efficiency and Application to Indian Agriculture." The American Economic Review 61 (March 1971): 94-109.

. "Profit, Supply and Factor Demand Functions." American Journal of Agricultural Economics 54 (February 1972): 94-109.

Lau, L. J. Applications of Profit Functions. The Stanford Institute for Mathematical Studies in the Social Sciences, Palo Alto: Stanford University, 1978, Reprint No. 269.

McFadden, D. "Factor Substitutability in the Economic Analysis of Production." Unpublished Ph.D. diss., University of Minnesota, 1962.

Meade, J. E. "Labour-Managed Firms in Conditions of Imperfect Competition." The Economic Journal (December 1974): 817-824.

Mikesell, J. L., and P. C. Mann. "Pricing by Rural Electric Cooperatives." Land Economics 52 (February 1976): 96-102.

Neuberg, L. G. "Two Issues in the Municipal Ownership of Electric Power

Distribution Systems." The Bell Journal of Economics 8, No. 1 (Spring 1977): 203-323.

Paroush, J., and N. Kahana. "Price Uncertainty and the Cooperative Firm." The American Economic Review 70, No. 1 (March 1980): 212-216.

Shephard, R. W. Cost and Production Functions. Princeton, NJ: Princeton University Press, 1953.

. Theory of Cost and Production Functions. Princeton, N.J.: Princeton University Press, 1970.

Stansell, S. R. "The Relative Risk and Efficiency of Cooperative Versus Commercial Telephone Companies." Agricultural Finance Review 40 (April 1980): 26-41.

Stansell, S. R., and D. R. Hollas. "An Examination of the Economic Efficiency of Class I Railroads: A Profit Function Analysis." Review of Industrial Organization 3, No. 4 (Fall 1988): 93-117.

"An Examination of the Relative Economic Efficiency of Mutual vs.

Stock Savings Institutions." Journal of Real Estate Finance and Economics 3 (1990): 73-89.

Uzawa, H. "Duality Principles in the Theory of Cost and Production." International Economic Review 5, No. 2 (May 1964): 216-220.

Yotopoulos, A. A., and L. J. Lau. "A Test For Relative Economic Efficiency: Some Further Results." The American Economic Review 63 (March 1973): 214-223. 